\title{
Green Nail Syndrome (Pseudomonas aeruginosa Nail Infection): Two Cases Successfully Treated with Topical Nadifloxacin, an Acne Medication
}

\author{
Simon Müller Myriam Ebnöther Peter Itin \\ Department of Dermatology, University Hospital Basel, Basel, Switzerland
}

\section{Key Words}

Green nail syndrome $\cdot$ Pseudomonas aeruginosa nail infection - Topical nadifloxacin · Acne medication

\begin{abstract}
Green nail syndrome (GNS) caused by Pseudomonas aeruginosa is the most common bacterial nail infection. The treatment of GNS is challenging in many cases and recommendations based on clinical trials are lacking. We report two cases with GNS successfully treated with off-label use of topical nadifloxacin, a fluoroquinolone approved for acne and bacterial skin infections in some countries.

(c) 2014 S. Karger AG, Basel
\end{abstract}

\section{Introduction}

Pseudomonas aeruginosa is the most prevalent pathogen of bacterial nail infections [1]. Green nail syndrome (GNS) is characterized by greenish chromonychia caused by pyocyanin, a metabolite produced by $P$. aeruginosa. GNS is usually restricted to one or two nails $[2,3]$. Predisposing factors are onychomycoses, nail diseases, working in wet conditions, diabetes mellitus, paronychia and immunosuppression, among others $[1,4,5]$. P. aeruginosa can be transmitted from GNS to wounds or surgical sites $[6,7]$ and thus lead to local and possibly systemic complications in immunocompromised individuals.

The treatment of GNS is challenging in many cases. Reported treatment options are systemic fluoroquinolones, topical octenidine $0.1 \%$ [2], topical aminoglycoside [5] and nail extraction [1,8]. Moreover, three patients with GNS successfully treated with topical 
nadifloxacin have been reported [3,4]. However, clinical trials of patients with GNS are currently lacking [1].

Nadifloxacin is a topical fluoroquinolone approved for the treatment of acne vulgaris in some countries (Germany, Italy, Spain, China, Japan and India, among others). It has a broadspectrum activity against Gram-positive (including methicillin-resistant Staphylococcus aureus), Gram-negative and anaerobic bacteria. Hence in some countries (e.g. India, Japan) it is also approved for the treatment of skin infections.

\section{Case Reports}

Case 1

A 64-year-old otherwise healthy female developed an asymptomatic greenish discoloration of the nail plate of the right middle finger within 2 months. The discoloration started from the proximal nail plate and proceeded to the distal margin. There was no history of nail trauma or previous nail diseases. Treatment with topical acetic acid and ethyl lactate during 1 month showed no effect. At first visit a greenish discoloration and mild onychodystrophy of the entire nail plate with distal onycholysis exclusively on the right middle finger were observed (fig. 1). The cuticula was also discolored, but no signs of paronychia were present. Bacteriologic culture of nail scrapings was positive for P. aeruginosa. KOH preparation (direct mycological microscopy) of nail scrapings was negative, but the culture was positive for Candida parapsilosis. Nadifloxacin (Nadixa ${ }^{\circledR}$ cream) was applied once daily on the nail plate for 6 weeks. The coinfection with C. parapsilosis was treated with itraconazole $100 \mathrm{mg}$ twice daily on weeks 1 and 5. The nail plate was cured within 6 months after the initiation of treatment (fig. 2).

\section{Case 2}

A 49-year-old female with bulimia suffered from recurrent onycholysis of the big toes due to tight shoes. Moreover a yellow-greenish discoloration persisted for several weeks on the right big toe. Treatment with topical amorolfine once per week showed no response. Lateral yellow-greenish discoloration, distal onychodystrophy and onycholysis exclusively on the right big toe without signs of paronychia (fig. 3) were present at first visit. Bacteriologic culture of nail scrapings was positive for $P$. aeruginosa. Fungal coinfection was excluded by $\mathrm{KOH}$ preparation and culture. Nadifloxacin (Nadixa ${ }^{\circledR}$ cream) was applied once daily on the nail plate for 6 weeks. The nail plate was cured within 4 months after the initiation of treatment (fig. 4).

\section{Discussion}

The clinical presentation of these two cases with P. aeruginosa nail infection in only one nail is typical. In both cases a predisposing factor was prevalent (onychomycosis in case 1, nail trauma in case 2). The observation of successful treatment with nadifloxacin is in line with previous reports [2-4]. Hence nadifloxacin might be an 'easy-to-handle', effective, nailpreserving and low-priced treatment option of GNS. As nadifloxacin is not approved for this indication, insurance confirmation of coverage should be provided.

Pseudomonas is not sensitive to itraconazole, hence the treatment effect on GNS in case $1 \mathrm{can}$ be attributed to nadifloxacin. However, the treatment of the coinfection (C. parapsilo- 


\begin{tabular}{l|l}
\hline DOI: $10.1159 / 000365863$ & $\begin{array}{l}\text { C 2014 S. Karger AG, Basel } \\
\text { www.karger.com/cde }\end{array}$ \\
\hline
\end{tabular}

Müller et al.: Green Nail Syndrome (Pseudomonas aeruginosa Nail Infection): Two Cases Successfully Treated with Topical Nadifloxacin, an Acne Medication

sis) with itraconazole in this case contributed to the cure of the nail. Thus, screening for fungal coinfections and if needed antifungal treatment in patients with GNS is crucial.

\section{Disclosure Statement}

The authors declare no conflicts of interest.

\section{References}

1 Nenoff P, Paasch U, Handrick W: Infections of finger and toe nails due to fungi and bacteria. Hautarzt 2014;65:337-348.

2 Rigopoulos D, Rallis E, Gregoriou S, Larios G, Belyayeva Y, Gkouvi K, Katsambas A: Treatment of Pseudomonas nail infections with 0.1\% octenidine dihydrochloride solution. Dermatology 2009;218:67-68.

$\checkmark 3$ Rallis E, Paparizos V, Flemetakis A, Katsambas A: Pseudomonas fingernail infection successfully treated with topical nadifloxacin in HIV-positive patients: report of two cases. AIDS 2010;24:1087-1088.

-4 Hengge UR, Bardeli V: Images in clinical medicine. Green nails. N Engl J Med 2009;360:1125.

5 Tosti A, Piraccini BM: Nail disorders; in Bolognia JL, Jorizzo JL, Schaffner JV (eds): Dermatology, ed 3. Edinburgh, Elsevier, 2012, pp 1134-1135.

-6 McNeil SA, Nordstrom-Lerner L, Malani PN, Zervos M, Kauffman CA: Outbreak of sternal surgical site infections due to Pseudomonas aeruginosa traced to a scrub nurse with onychomycosis. Clin Infect Dis 2001;33:317-323.

7 Mermel LA, McKay M, Dempsey J, Parenteau S: Pseudomonas surgical-site infections linked to a healthcare worker with onychomycosis. Infect Control Hosp Epidemiol 2003;24:749-752.

$\checkmark 8$ Cho SB, Kim HS, Oh SH: Green nail syndrome associated with military footwear. Clin Exp Dermatol 2008;33: 791-793. 


\section{Case Reports in Dermatology}

\begin{tabular}{l|l}
\hline DOI: $10.1159 / 000365863$ & $\begin{array}{l}\text { (c) 2014 S. Karger AG, Basel } \\
\text { www.karger.com/cde }\end{array}$ \\
\hline
\end{tabular}

Müller et al.: Green Nail Syndrome (Pseudomonas aeruginosa Nail Infection): Two Cases Successfully Treated with Topical Nadifloxacin, an Acne Medication

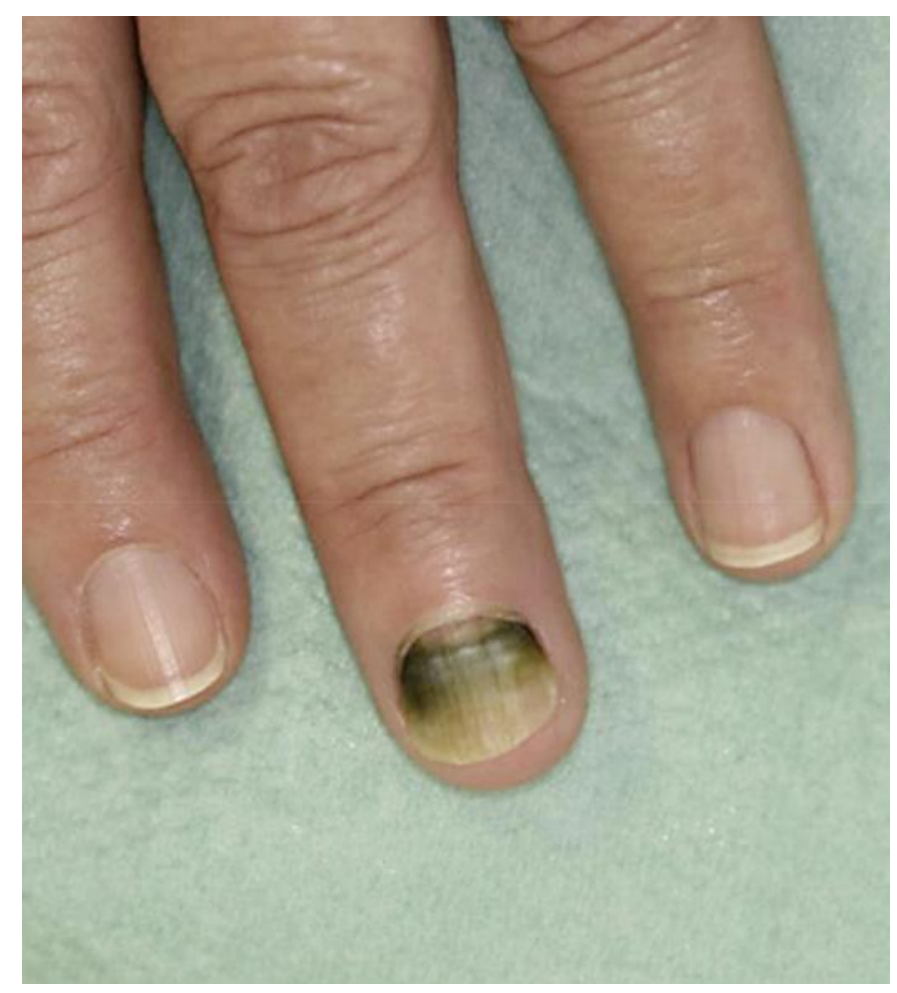

Fig. 1. Case 1. Coinfection with P. aeruginosa and C. parapsilosis. Presentation at first visit: greenish discoloration of the right middle finger.
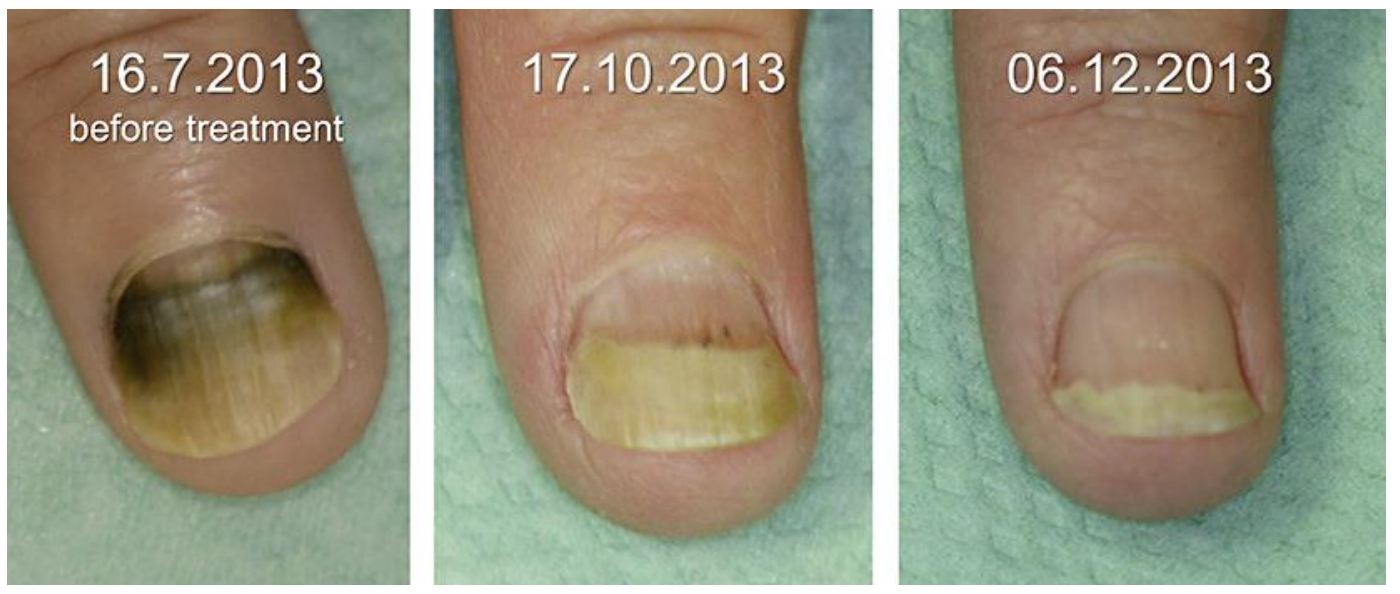

Fig. 2. Case 1. Course after treatment with nadifloxacin once daily for 6 weeks and itraconazole $100 \mathrm{mg}$ twice daily on weeks 1 and 5 . 


\section{Case Reports in Dermatology}

\begin{tabular}{l|l}
\hline DOI: $10.1159 / 000365863$ & $\begin{array}{l}\text { ○ 2014 S. Karger AG, Basel } \\
\text { www.karger.com/cde }\end{array}$ \\
\hline
\end{tabular}

Müller et al.: Green Nail Syndrome (Pseudomonas aeruginosa Nail Infection): Two Cases Successfully Treated with Topical Nadifloxacin, an Acne Medication

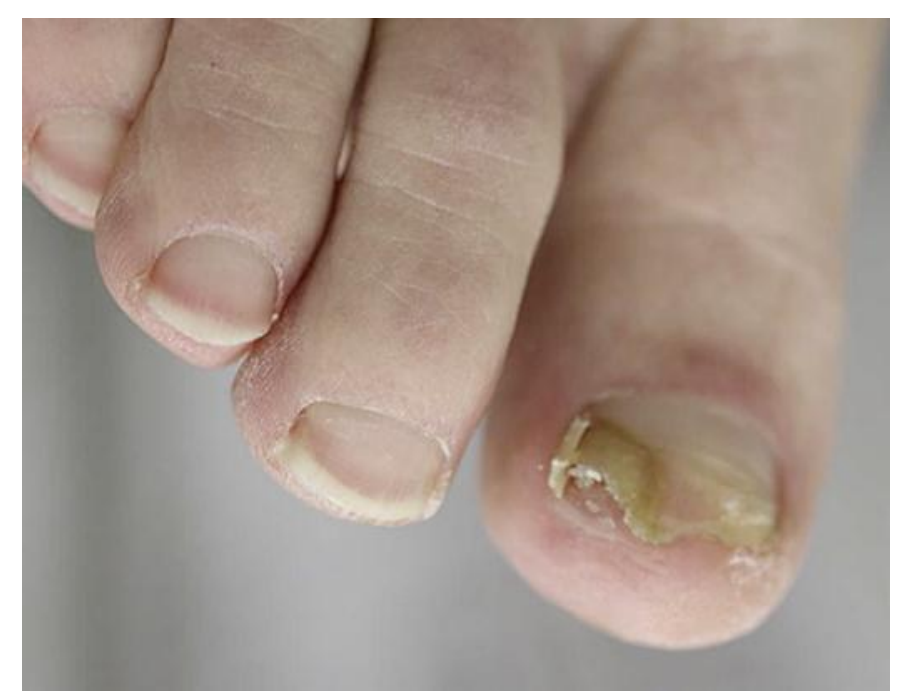

Fig. 3. Case 2. Infection with P. aeruginosa. Presentation at first visit: yellow-greenish discoloration, distal onychodystrophy and onycholysis on the right big toe.
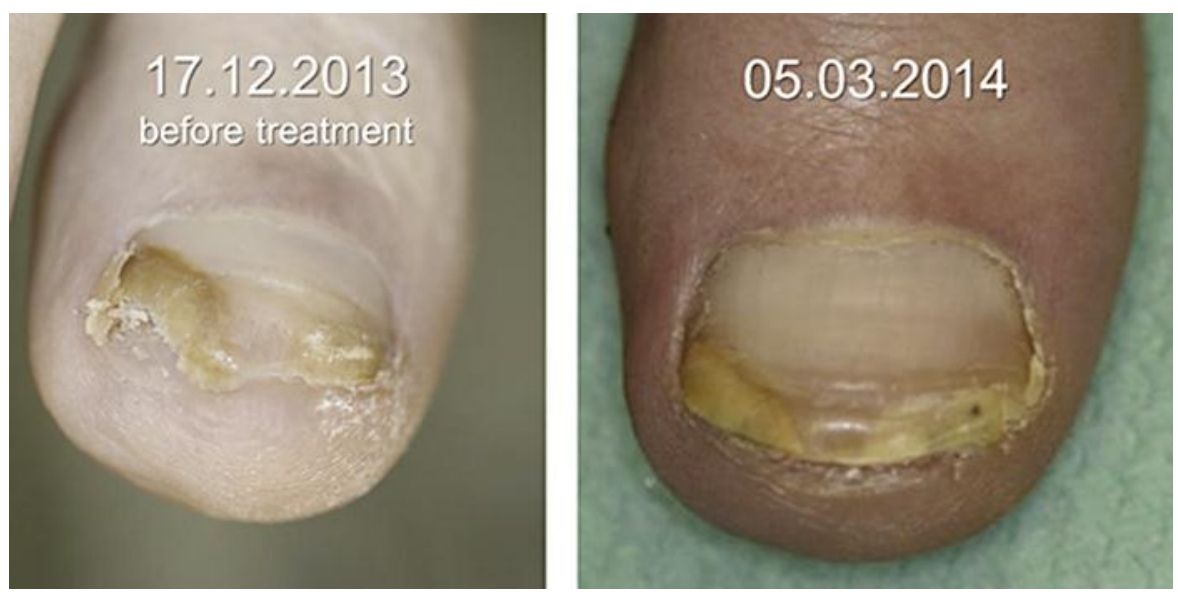

Fig. 4. Case 2. Course after treatment with nadifloxacin once daily for 6 weeks. 